\title{
Cerium (Ce) Affects the Phenological Cycle and the Quality of Tulip (Tulipa gesneriana L.)
}

\author{
Gómez-Navor, Tsujmejy ${ }^{1}$; Gómez-Merino, Fernando C. ${ }^{1}$; Alcántar-González, Gabriel ${ }^{1}$; \\ Fernández-Pavía, Y. Leticia ${ }^{1}$; Trejo-Téllez, Libia I. ${ }^{1^{*}}$
}

${ }^{1}$ Colegio de Postgraduados Campus Montecillo. Montecillo, Texcoco, Estado de México, México. C. P. 56230.

*Corresponding author: tlibia@colpos.mx

\begin{abstract}
Objective: To study the effect of cerium (Ce) applied in a nutrient solution during the productive cycle, on the duration of the phases of the phenological cycle of tulip (Tulipa gesneriana L.) cv. Jan van Nes.

Design/Methodology/Approach: Commercial bulbs (caliber 12+) were planted under shade cloth conditions during the autumn-winter period. The levels of $\mathrm{Ce}$ used were 5, 15 and $15 \mu \mathrm{M}$ from $\mathrm{CeCl}_{3} 7 \mathrm{H}_{2} \mathrm{O}$; Ce was applied in the nutrient solution from the first day of the sowing, apart from the control without its application.

Results: The different concentrations of Ce stimulated bulb sprouting. The low concentration of Ce ( $5 \mu \mathrm{M})$ promoted the early formation of floral buds and their coloration. Hence, the application of $5 \mu \mathrm{M} C e$ induces flowering of the tulip without exhibiting changes in the period of time to reach senescence. When $25 \mu \mathrm{M}$ Ce were applied, the opposite effects were observed. The duration of the flower was not significantly affected by the treatments.
\end{abstract}

Study Limitations/Implications: This study was made only in one cultivar of tulip.

Findings/Conclusions: The application of $5 \mu \mathrm{M}$ of Ce had a positive effect in the tulip cycle, by stimulating bulb sprouting, the formation of the floral bud, the coloration, and the induction of the flowering cycle.

Keywords: biostimulation, rare earth elements, hormesis, ornamentals.

\section{INTRODUCTION}

are earth elements (REE) are a family of 17 chemical elements formed by group III of the periodic table (scandium and yttrium) and the series of lanthanides (from lanthanum and lutetium) which exhibit chemical similarities as a group, while they express individually distinctive and varied electronic properties (Voncken, 2016; Cheisson and Schelter, 2019).
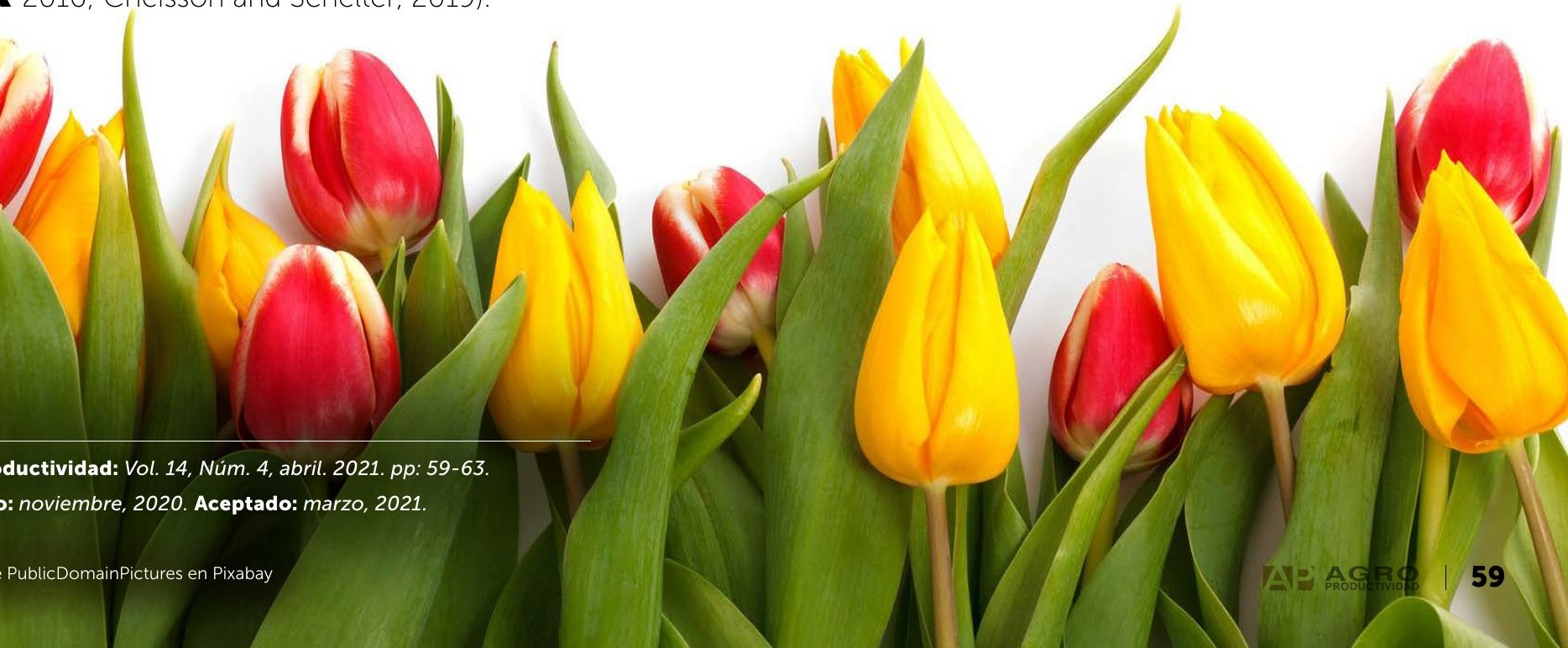
For this study, cerium (Ce) is of particular importance, for which both positive and negative effects are reported in plants, with these being dependent on the dose, time of exposure, method of application, plant species, growth conditions, $\mathrm{pH}$, as well as nutrient interaction, development stage, among other factors (Zhang et al., 2013; Ramos et al., 2016, Xu et al., 2016; García-Jiménez et al., 2017).

On the other hand, tulip is the main ornamental bulb plant produced worldwide. The Netherlands has $60 \%$ of global production. In recent years, the studies performed in tulip have centered on increasing stem enlongation, bulb quality, and stimulating early flowering (Kurtar and Ayan, 2005). In this study we aimed to evaluate the effect of Ce supplied during the productive cycle in nutrient solution, on the duration of the phenological cycle stages of tulip cv. Jan van Nes.

\section{MATERIALS AND METHODS}

\section{Plant Material and Experiment Conditions}

The experiment was developed in a greenhouse under $50 \%$ black monofilament shadecloth. The average temperature that was found during the cultivation cycle was $14{ }^{\circ} \mathrm{C}, 52 \%$ of relative humidity, and light intensity of 125 lumen $\mathrm{m}^{-2}$.

Commercial cultivar Jan van Nes (caliber 12+) tulip bulbs were used. This cultivar produces intense yellow flowers. Planting was done in 7-inch pots, and a mixture of red tezontle, perlite (Agrolita ${ }^{M R}$ ) and peat (Promix ${ }^{\circledR} \mathrm{FLX}$ ) in a proportion of 70:20:10 (v:v:v) was used as substrate. Before planting, the bulbs were previously disinfected.

Steiner's nutrient solution (Steiner, 1984) at 50\% was used for the fertilization, which contained in $\mathrm{g} \mathrm{L}^{-1}: 0.5313$ $\mathrm{Ca}\left(\mathrm{NO}_{3}\right)_{2} 4 \mathrm{H}_{2} \mathrm{O}, 0.2464 \mathrm{MgSO}_{4} 7 \mathrm{H}_{2} \mathrm{O}, 0.0680 \mathrm{KH}_{2} \mathrm{PO}_{4}$, $0.1516 \mathrm{KNO}_{3}$ and $0.1306 \mathrm{~K}_{2} \mathrm{SO}_{4}$; it was complemented with a commercial mixture of micronutrients, TradeCorp ${ }^{\circledR} \mathrm{AZ}$, added at $0.0665 \mathrm{~g} \mathrm{~L}^{-1}$ of the nutrient solution. The $\mathrm{pH}$ of the nutrient solution was adjusted to 5.3, using concentrated $\mathrm{H}_{2} \mathrm{SO}_{4}$. The nutrient solution was supplied in the localized drip irrigation system using $1 / 2$ HP pumps.

\section{Treatment and Experiment Design}

Different concentrations of $\mathrm{Ce}$ added to the nutrient solution were evaluated. The levels of Ce used were 5 , 15 and $25 \mu \mathrm{M}$ from $\mathrm{CeCl}_{3} 7 \mathrm{H}_{2} \mathrm{O}$; in addition to a control, without application of $\mathrm{Ce}$.
The experiment was established in a completely randomized design (CRD), and the experimental unit consisted of one plant per pot and each treatment had eight repetitions. The application of the treatments started from the first day of planting the bulbs.

\section{Evaluated Variables}

The influence of $\mathrm{Ce}$ on bulb emergence, formation of flower bud, coloration of buds, anthesis and senescence; these variables were evaluated at different days after planting (dap).

Emergence of bulbs was characterized with the appearance of the apical meristem. The coloration was defined when the flower bud presented changes in its coloration (green tepals with green border). Anthesis was defined as the days in full flowering, the flower was completely open, and the gyneceum showed the three lobes of the stigma and all the completely formed stamens. The plant was considered senescent when the flower presented withering and tepal fall.

The duration of the flower was estimated by counting the days from anthesis until senescence.

\section{Statistical Analysis}

With the data obtained, an analysis of variance was performed and the means were compared using Tukey's test with a significance of $\alpha=0.05$. The statistical analysis system version 9.4 (SAS Institute, 2013) was used.

\section{RESULTS AND DISCUSSION}

The cultivation cycle of the tulip plants was prolonged on average 4.28 days with the addition of $25 \mu \mathrm{M}$ Ce in the nutrition solution, compared with the control plants that completed their cycle in 57.14 days, whereas the other concentrations had a similar duration to the control (data not shown).

Bulb emergence was stimulated with the addition of different concentrations of $\mathrm{Ce}$ in the nutrition solution, which happened on average at 6 dap, while the emergence of the apical meristem took place 2 days later ( 8 dap) in control plants without addition of $\mathrm{Ce}$ (Figure 1).

In a similar way as in bulb emergence, the formation of the flower bud was ahead in 1.85 and 3.25 days in treated plants with 5 and $15 \mu \mathrm{M}$ Ce, respectively, compared to the control where this event happened at 
10

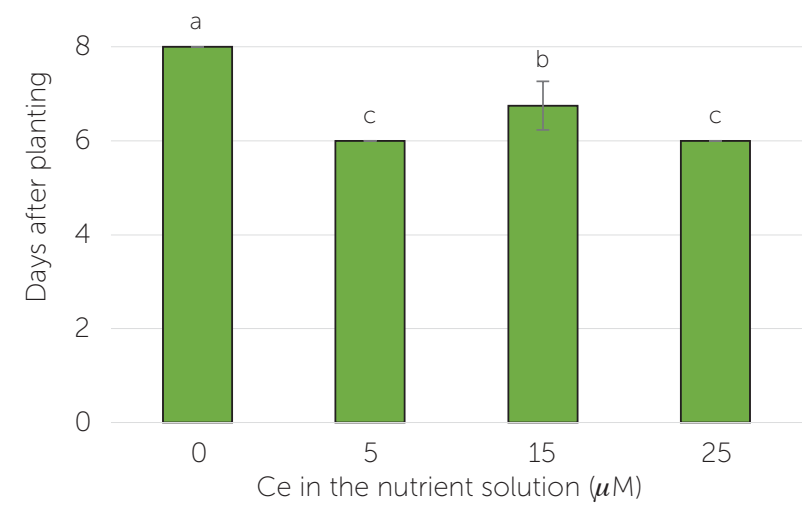

Figure 1. Sprouting of tulip bulbs treated with different concentrations of $\mathrm{Ce}$ in the nutrient solution during the productive cycle. Means \pm SD with different letters indicate significant differences (Tukey, $p \leq 0.05$ ). $n=8$.

38.62 dap. In contrast, the dose of $25 \mu \mathrm{M}$ Ce delayed the formation of the flower bud by 0.5 days, also compared to the control (Figure 2a). Plants treated with $5 \mu \mathrm{M} \mathrm{Ce}$ presented coloring of the bud in a shorter time $(44.75$ dap) compared to the control (46.25 dap) as observed in Figure 2b; as consequence, the period of anthesis was 1.14 days before than in the control plants (50.71 dap; Figure 2c). Meanwhile, in the plants that were exposed to $25 \mu \mathrm{M}$ Ce, coloring of the flower bud (2.75 days; Figure 2b) and anthesis (3.29 days; Figure 2c) were delayed compared to the control plants.

In plants treated with $\mathrm{Ce}$, the period of time to reach senescence was not different from the control, except in the plants treated with $25 \mu \mathrm{M} \mathrm{Ce}$, where the period to reach senescence was prolonged on average in 4.28 days compared to control plants (57.14 dap) (Figure 3).

The duration of the flower was estimated by counting the days from the period of anthesis until senescence of the flower, that is, when the withering and fall of tepals happened. The doses of $\mathrm{Ce}$ of 5 and $25 \mu \mathrm{M}$ prolonged the life of the flower in 1.15 and 1.05 days, respectively, compared to the control where the life of the flower was 6.42 days, although these increases were not significant (Figure 4).

\section{DISCUSSION}

In this study, the application of the different doses of $\mathrm{Ce}$ in the nutrition solution stimulated the emergence of the bulbs, advancing this process 2 days compared with the control ( 8 dap); however, only the low dose of $\mathrm{Ce}$ $(5 \mu \mathrm{M})$ affected positively the formation of the flower bud, and therefore promoted the early coloration and flowering in tulip, although the period of time to reach senescence was equal to the that of the control plants. Contrasting results were obtained in plants treated with $25 \mu \mathrm{M}$ of $\mathrm{Ce}$, where all the phases evaluated were delayed compared to the control and the period to reach senescence was longer. The reason why the low dose of Ce stimulates the emergence of the bulbs and advances the flowering period is probably that $\mathrm{Ce}$
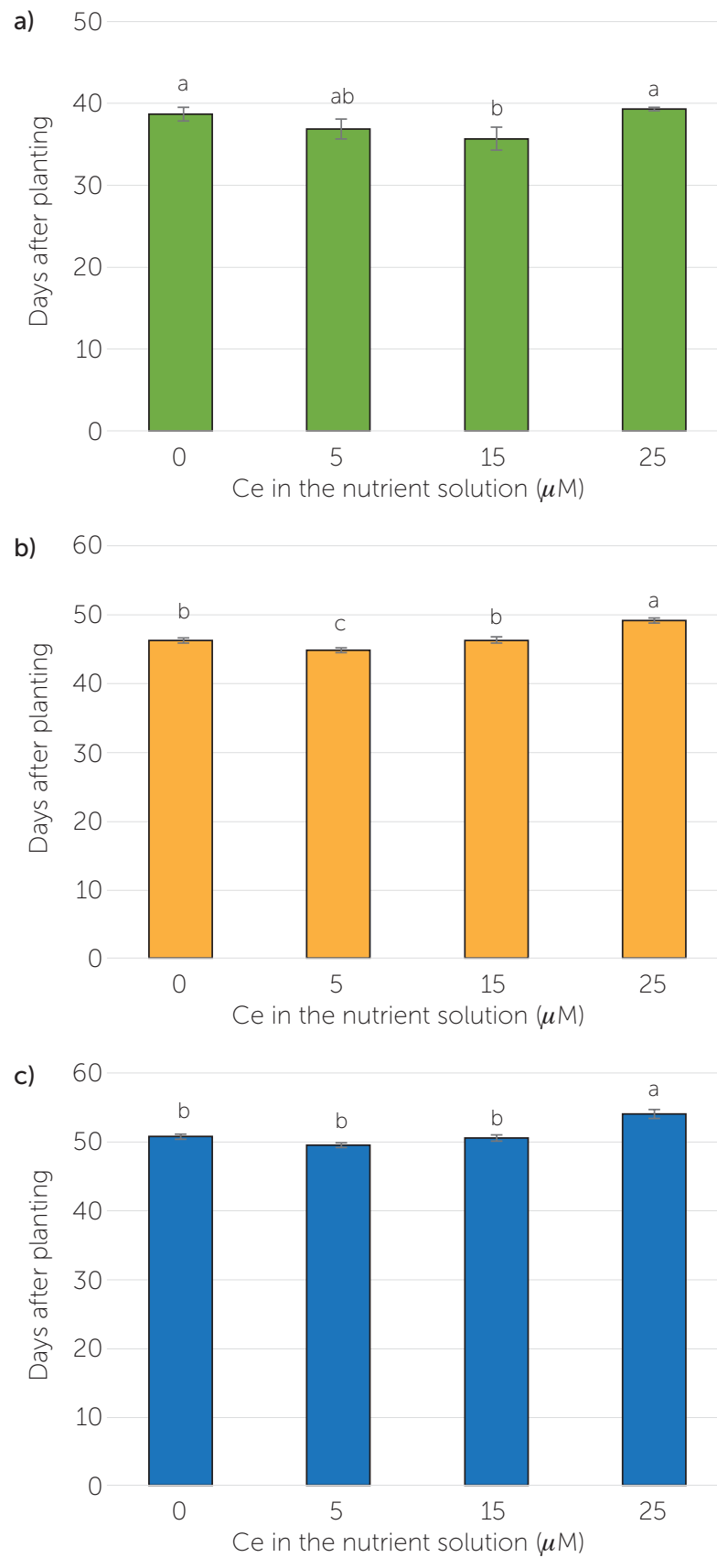

Figure 2. Flower bud formation (a), bud coloration (b) and anthesis (c) in tulip plants treated with different concentrations of $\mathrm{Ce}$ in the nutrient solution during the productive cycle. Means \pm SD with different letters in each subfigure indicate significant differences (Tukey, $\mathrm{p} \leq 0.05$ ). $n=8$. 


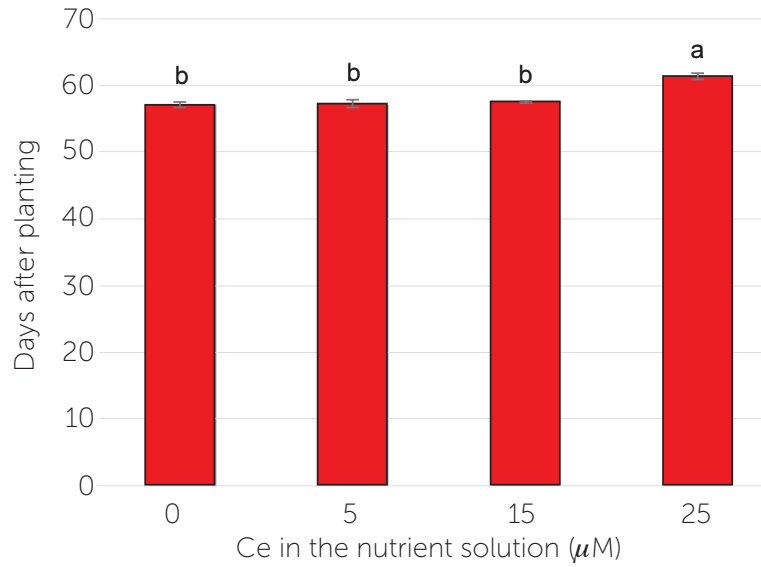

Figure 3. Senescence of tulip plants treated with different concentrations of $\mathrm{Ce}$ in the nutrient solution during the productive cycle. Means \pm SD with different letters indicate significant differences (Tukey, $\mathrm{p} \leq 0.05$ ). $n=8$.

is related to some plant hormone that favors these processes.

The moment of transition of plant growth to flowering is important in agriculture. Flowering is regulated by a complex network of genes that integrate multiple environmental signs and endogenous signs for flowering to take place in the adequate moment: hormonal regulation, signaling and homeostasis are very important in this process (Galvão and Schmid, 2014; Campos-Rivero et al., 2017). In tulip, endogenous plant hormones that are related directly with bulb emergence and flowering are gibberellins (CocozzaTalia and Stellacci, 1979). In various studies it has been found that the production of plant hormones can be affected by the presence of REE; in some cases, REE can act synergically with some plant hormones that can stimulate germination and flowering (He and Loh, 2002: Wang et al., 2014; Wang et al., 2015; Ramos et al., 2016). Despite this, it is not completely clear whether REE are directly involved with the signaling of plant hormones; likewise, the responses of stimulus or inhibition of plant hormones are variable between species and different REE (Wang et al., 2015). In Arabidopsis plants, La interacts with the signal from abscisic acid (ABA) on root growth, in addition to a concentration of $10 \mu \mathrm{mol}$ $\mathrm{La}^{+3} \mathrm{~L}^{-1}$ which increases the rate of seed germination when these are inhibited by ABA (Wang et al., 2014). In Dendrobium densiflorum plant, the application of

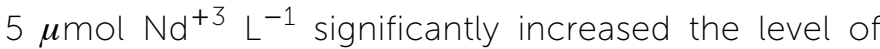
endogenous indole-3-acetic acid (IAA) and the rate of IAA and cytokinins during the formation process of the root primordium, which favored the rooting

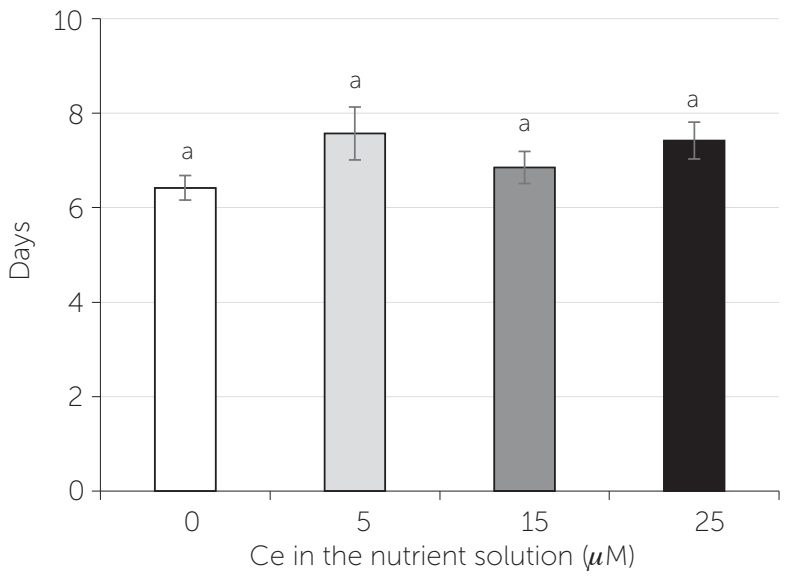

Figure 4. Duration of the flower in tulip plants treated with different concentrations of $\mathrm{Ce}$ in the nutrient solution during the productive cycle. Means \pm SD with different letters indicate significant differences (Tukey, $p \leq 0.05$ ). $n=8$.

of cuttings (Luo et al., 2008). In Arabidopsis thaliana, low concentrations of $\mathrm{Ce}(0.5-10.0 \mu \mathrm{M})$ significantly stimulated flowering and the number of flowers per plant, which is why it was considered that Ce and other rare earth elements can have a potential to develop as non-hormonal flowering promoting agents for certain kinds of crops (He and Loh, 2000). He and Loh (2002) pointed out that these responses were related with a higher production of endogenous cytokinins in the plant, which is why they suggested that REE have a synergic effect with this plant hormone.

On the other hand, the duration of the potted flower was prolonged 1.15 and 1.05 days with a dose of Ce of 5 and $25 \mu \mathrm{M}$, respectively, in comparison to the control 16.42 days), although these increases were not statistically significant

\section{CONCLUSION}

It is concluded that the application of $5 \mu \mathrm{M}$ Ce has a positive effect on the growth, development and reproductive parameters of tulip, when stimulating the emergence of the bulb, formation of the flower bud, coloration, and advancing the flowering period.

\section{REFERENCES}

Campos-Rivero, G., Osorio-Montalvo, P., Sánchez-Borges, R., UsCamas, R., Duarte-Aké, F., \& De-la-Peña, C. (2017). Plant hormone signaling in flowering: an epigenetic point of view. Journal of Plant Physiology, 214, 16-27. Doi: 10.1016/j. jplph.2017.03.018

Cheisson, T., \& Schelter, E. J. (2019). Rare earth elements: Mendeleev's bane, modern marvels. Science, 363(6426), 489-493. Doi: 10.1126/science.aau7628 
Cocozza-Talia, M., \& Stellacci, P. (1979). A research on the effect of gibberellin upon tulip flowering. Acta Horticulturae, 91, 167-172. Doi: 10.17660/ActaHortic.1979.91.18

Galvão, V. C., \& Schmid, M. (2014). Regulation of flowering by endogenous signals. In F. Fornara (Ed.), Advances in Botanical Research (pp. 63-102). Amsterdam, The Netherlands: Elsevier.

García-Jiménez, A., Gómez-Merino, F. C., Tejeda-Sartorius, O., \& Trejo-Téllez, L. I. (2017). Lanthanum affects bell pepper seedling quality depending on the genotype and time of exposure by differentially modifying plant height, stem diameter and concentrations of chlorophylls, sugars, amino acids, and proteins. Frontiers in Plant Science, 8, 308. Doi: 10.3389/fpls.2017.00308

He, Y. W., \& Loh, C. S. (2000). Cerium and lanthanum promote floral initiation and reproductive growth of Arabidopsis thaliana. Plant Science, 159(1), 117-124. Doi: 10.1016/S0168-9452(00)00338-1

He, Y. W., \& Loh, C. S. (2002). Induction of early bolting in Arabidopsis thaliana by triacontanol, cerium and lanthanum is correlated with increased endogenous concentration of isopentenyl adenosine (iPAdos). Journal of Experimental Botany, 53(368), 505-512. Doi: 10.1093/jexbot/53.368.505

Kurtar, E. S., \& Ayan, A. K. (2005). Effect of gibberellic acid (GA3) and indole-3-acetic acid (IAA) on flowering, stalk elongation and bulb characteristics of tulip (Tulipa gesneriana var. cassini). Pakistan Journal of Biological Sciences, 8(2), 273-277.

Luo, J., Zhang, J., \& Wang, Y. (2008). Changes in endogenous hormone levels and redox status during enhanced adventitious rooting by rare earth element neodymium of Dendrobium densiflorum shoot cuttings. Journal of Rare Earths, 26(6), 869-874. Doi: 10.1016/S1002-0721(09)60023-5

Ramos, S. J., Dinali, G. S., Oliveira, C., Martins, G. C., Moreira, C. G., Siqueira, J. O., \& Guilherme, L. R. (2016). Rare earth elements in the soil environment. Current Pollution Reports, 2(1), 28-50. Doi: 10.1007/ s40726-016-0026-4

SAS Institute. (2013). Base SAS 9.4. Procedures Guide: Statistical Procedures. Second edition. Cary, NC, USA: SAS Institute Inc

Steiner, A. A. (1984). The universal nutrient solution. In Proceedings Sixth International Congress on Soilless Culture (pp. 633-650). Lunteren, Wageningen, The Netherlands: ISOSC.

Voncken, J. H. L. (2016). The ore minerals and major ore deposits of the rare earths. In J. H. L. Voncken (Ed.), The Rare Earth Elements (pp. 15-52). Cham, Switzerland, Springer. doi: 10.1007/978-3-319-26809-5

Wang, J., Wang, L., Hu, T., Li, W., \& Xue, S. (2014). Effects of lanthanum on abscisic acid regulation of root growth in Arabidopsis. Journal of Rare Earths, 32(1), 78-82. Doi: 10.1016/S1002-0721(14)60035-1

Wang, L., Zhang, X., Zhou, Q., \& Huang, X. (2015). Effects of terbium (III) on signaling molecules in horseradish. Biological Trace Element Research, 164(1), 122-129. Doi: 10.1007/s12011-014-0209-Z

Xu, Q. M., Wang, Y. Z., Liu, H., \& Cheng, J. S. (2016). Physiological responses and chromosomal aberration in root tip cells of Allium sativum L. to cerium treatments. Plant and Soil, 409(1-2), 447-458. Doi: 10.1007/s11104-016-2978-y

Zhang, C., Li, Q., Zhang, M., Zhang, N., \& Li, M. (2013). Effects of rare earth elements on growth and metabolism of medicinal plants. Acta Pharmaceutica Sinica B, 3(1), 20-24. Doi: 10.1016/j. apsb.2012.12.005

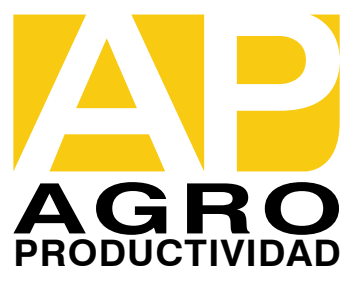

